\title{
Congenital Athymia: Genetic Etiologies, Clinical Manifestations, Diagnosis, and Treatment
}

\author{
Cathleen Collins ${ }^{1} \cdot$ Emily Sharpe $^{2} \cdot$ Abigail Silber $^{2} \cdot$ Sarah Kulke $^{3}$ - Elena W. Y. Hsieh ${ }^{4,5}$
}

Received: 4 January 2021 / Accepted: 3 May 2021 / Published online: 13 May 2021

(c) The Author(s) 2021

\begin{abstract}
Congenital athymia is an ultra-rare disease characterized by the absence of a functioning thymus. It is associated with several genetic and syndromic disorders including FOXN1 deficiency, 22q11.2 deletion, CHARGE Syndrome (Coloboma, Heart defects, Atresia of the nasal choanae, Retardation of growth and development, Genitourinary anomalies, and Ear anomalies), and Complete DiGeorge Syndrome. Congenital athymia can result from defects in genes that impact thymic organ development such as FOXN1 and PAXI or from genes that are involved in development of the entire midline region, such as TBXI within the 22q11.2 region, $C H D 7$, and FOXI3. Patients with congenital athymia have profound immunodeficiency, increased susceptibility to infections, and frequently, autologous graft-versus-host disease (GVHD). Athymic patients often present with absent $\mathrm{T}$ cells but normal numbers of $\mathrm{B}$ cells and Natural Killer cells $\left(\mathrm{T}^{-} \mathrm{B}^{+} \mathrm{NK}^{+}\right)$, similar to a phenotype of severe combined immunodeficiency (SCID); these patients may require additional steps to confirm the diagnosis if no known genetic cause of athymia is identified. However, distinguishing athymia from SCID is crucial, as treatments differ for these conditions. Cultured thymus tissue is being investigated as a treatment for congenital athymia. Here, we review what is known about the epidemiology, underlying etiologies, clinical manifestations, and treatments for congenital athymia.
\end{abstract}

Keywords Congenital athymia $\cdot$ midline defects $\cdot$ DiGeorge $\cdot$ T cells $\cdot$ immunodeficiency

\section{Introduction}

Congenital athymia is an ultra-rare condition [1] characterized by the absence of a thymus at birth. The thymus is crucial for the maturation and selection of $\mathrm{T}$ cells, and infants born without a thymus suffer from profound immunodeficiency [2]. Failure to promptly diagnose this disease and institute measures to prevent exposure to infectious agents can be fatal. Currently, all 50 states in the USA

Elena W. Y. Hsieh

elena.hsieh@cuanschutz.edu

1 Department of Pediatrics, Division of Allergy Immunology, Rady Children's Hospital, University of California San Diego, San Diego, CA, USA

2 Trinity Life Sciences, Waltham, MA, USA

3 Enzyvant Therapeutics, Inc, Cambridge, MA, USA

4 Department of Pediatrics, Section of Allergy and Immunology, Children's Hospital Colorado, University of Colorado School of Medicine, Aurora, CO, USA

5 Department of Immunology and Microbiology, University of Colorado School of Medicine, Aurora, CO, USA offer newborn screening for $\mathrm{T}$ cell receptor excision circles (TRECs) which will identify infants who may have congenital athymia in addition to severe combined immunodeficiency (SCID) [3, 4]. The diagnosis requires confirmation of low naïve $\mathrm{T}$ cells by flow cytometry [5].

Multiple genetic abnormalities, congenital syndromes, and environmental factors are associated with congenital athymia, and the care of these infants is complex. While 22q11.2 deletion-associated with DiGeorge Syndrome (DGS) is the most commonly described genetic defect associated with congenital athymia, FOXN1, PAXI, and others have also been identified as potentially causative [5-8]. Among patients with DGS, the majority have partial DGS (pDGS), which is characterized by T cell deficiency, but not athymia [9-11]. Complete DGS (cDGS) refers to patients with congenital athymia; cDGS patients account for a minor proportion of all DGS patients [2, 11, 12]. CHARGE Syndrome (Coloboma, Heart defects, Atresia of the nasal choanae, Retardation of growth and development, Genitourinary anomalies, and Ear anomalies) has also been shown to be associated with congenital athymia [5]. 
Environmental exposures have also been implicated, such as diabetic embryopathy and retinoic acid exposure [5, 13].

Hallmarks of congenital athymia include a profound $\mathrm{T}$ cell deficiency, frequent infections, susceptibility to opportunistic infections, and propensity to develop autologous graft-versus-host disease (GVHD), or in the clinical picture of cDGS, as having an 'atypical' phenotype [5, 7]. Autologous GVHD is often the term used to refer to auto-reactive $\mathrm{T}$ cells that escaped $\mathrm{T}$ cell selection due to lack of thymus. These T cells often produce a cellular infiltrate and organ damage $[14,15]$. It is critical to ensure that these infants do not receive immunizations prior to immune reconstitution as live vaccines may be fatal. Hematopoietic stem cell transplantation has not proved effective in treating these patients $[16,17]$. A therapy currently under investigation is the implantation of cultured thymus tissue $[14,18]$.

\section{Etiology of Congenital Athymia}

The thymus is a crucial element of the immune system because it is the only organ where thymocytes can mature, be selected, and ultimately survive to become naïve $\mathrm{T}$ cells [19]. T cell precursors emerge from the bone marrow and migrate to the thymus for maturation. These cells enter the thymus at the junction of the cortex and medulla and travel to the subcapsular region of the thymic cortex. In the subcapsular region, they undergo differentiation that results in expression of the $\mathrm{T}$ cell receptor (TCR). They travel from the subcapsular region to the cortex where they begin to express CD4 and CD8 receptors. In the cortex, T cell precursors undergo positive selection via interactions with cortical thymic epithelial cells (cTECs) expressing self-antigens on MHC I and II. T cell precursors then travel to the medulla and undergo negative selection through interaction with medullary thymic epithelial cells (mTECs) that express tissue restricted antigens from different organs through the transcriptional regulator Aire and others [20, 21]. Subsequent downregulation of either $\mathrm{CD} 4$ or $\mathrm{CD} 8$ produces naïve single positive cells that are ready to exit the thymus and enter the peripheral bloodstream.

\section{Thymus Development Overview}

One of the most characteristic features of human embryonic development of the head and neck are the pharyngeal arches (Fig. 1). The pharyngeal arches are lined internally by endoderm, externally by ectoderm, and each contains a mesenchymal tissue center derived from mesoderm and neural crest cells. Pharyngeal pouches develop from the internal endoderm and give rise to different organs. During embryonic development, the third pharyngeal pouch endoderm gives rise to the thymus and parathyroid glands, as shown in Fig. 2. Several genes have been identified that regulate the early phases of pharyngeal pouch formation and patterning, as well as subsequent thymus organ development (Table 1).

Congenital athymia can result from genetic defects that are (1) specific to thymic organ development or (2) involved in the broader development of the entire midline region (Fig. 1).

\section{Genetic Defects Specific to Thymic Organ Development}

\section{FOXN1}

Forkhead Box N1 (FOXN1) is the most well-known gene specific to thymic development. FOXN1 belongs to the forkhead box gene family of transcription factors and is involved in the development, differentiation, and maintenance of TECs in embryonic and postnatal life, and growth and differentiation of skin epithelial cells [22-26]. The clinical presentation of patients with homozygous mutations in FOXN1 illustrates its key role. Patients characteristically present with congenital athymia, congenital alopecia, and nail dystrophy [27, 28]. Patients with homozygous FOXN1 mutations typically have low $\mathrm{T}$ cell numbers and function, and normal B and Natural Killer (NK) cells, though possible reduced B cell function. To date, three distinct homozygous mutations have been identified in approximately 10 patients [7, 28-31]. All three mutations result in loss of function of the protein; two are located in the $\mathrm{N}$-terminus domain while one is located in the forkhead domain.

Heterozygous mutations in FOXN1 have also been described [29, 32-34]. Bosticardo et al. identified 20 distinct heterozygous loss-of-function FONX1 gene variants in pediatric and adult patients [33]. Variants occurred throughout the FOXN1 gene, but clustered in the forkhead and C-terminal domains. Most pediatric patients with heterozygous FOXN1 mutations did not have complete congenital athymia but instead presented with low levels of TRECs (identified by newborn screening) and $\mathrm{T}$ cell lymphopenia at birth. Importantly, their lymphopenia tended to improve over time; longitudinal analysis found that although CD8 + T cell lymphopenia persisted, $\mathrm{CD}^{+} \mathrm{T}$ cell lymphopenia became less severe past 2 years of age. For adult patients, $\mathrm{T}$ cell counts were typically within normal range, with the exception of $\mathrm{CD} 8^{+} \mathrm{T}$ cell counts which were lower than normal. Though difficult to interpret the significance of these results, a thymic shadow was absent in 4 out of 13 pediatric patients evaluated with a heterozygous FOXN1 variant. To understand the underlying cause for this immune phenotype, the authors created Foxn $1^{n u /+}$ mice and found a considerable decrease in early thymic progenitors and expression 

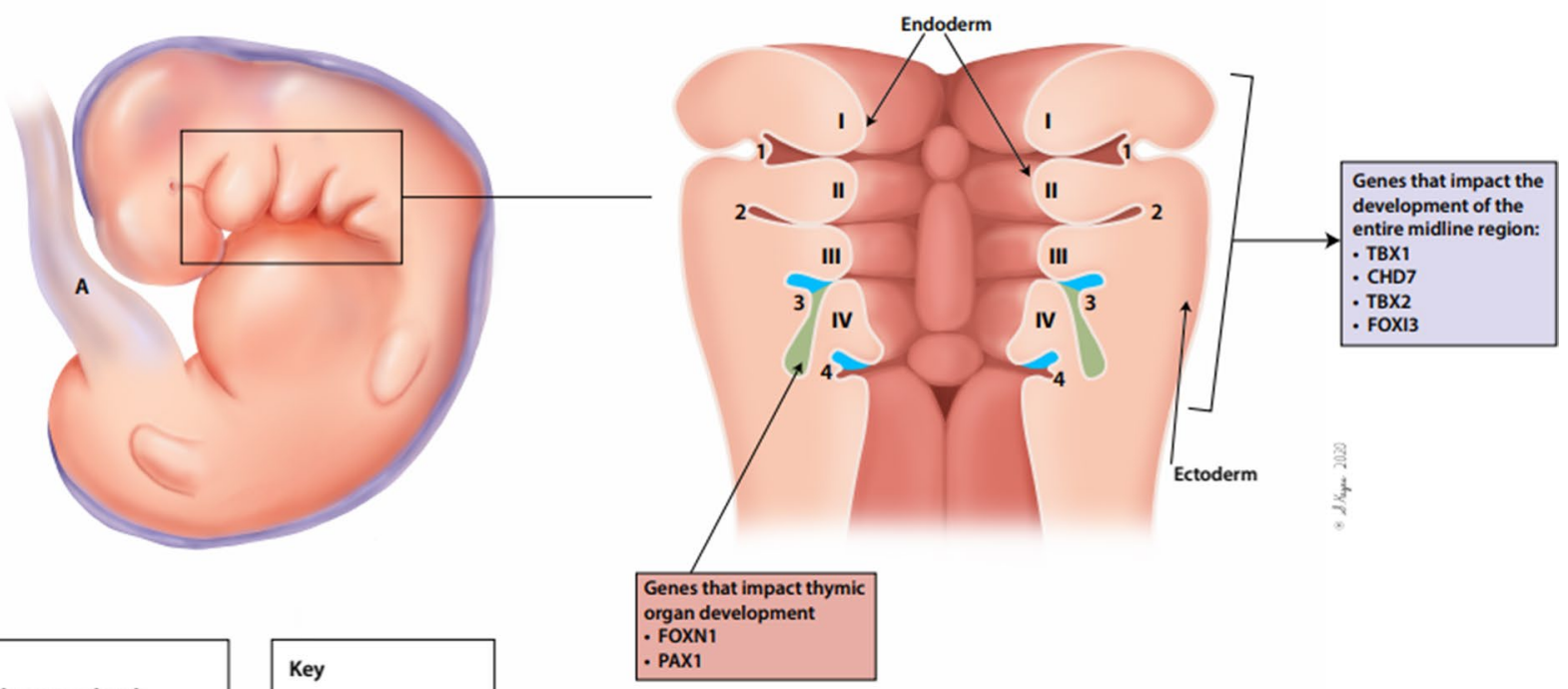

I= First pharyngeal arch

II = Second pharyngeal arch

III = Third pharyngeal arch

IV = Fourth pharyngeal arch

1 = First pharyngeal pouch

2 = Second pharyngeal pouch

$3=$ Third pharyngeal pouch

$4=$ Fourth pharyngeal pouch

$A=$ Umbilical cord

Fig. 1 Genetic etiologies of congenital athymia and impact on embryogenesis. Artistic rendering of the different etiologies associated with congenital athymia and how they impact the developing embryo.

of Foxn1 transcriptional targets early in the first weeks of life that trended toward normal over time. Consistent with the nude/SCID phenotype, several pediatric and adult patients with heterozygous FOXN1 mutations also had nail dystrophy, slight hair thinning or hair loss, and eczema or other atopic dermatitis manifestations [33].

Compound heterozygous mutations have also been reported in two patients described as having a presentation consistent with $\mathrm{T}^{-/ l o} \mathrm{~B}^{+} \mathrm{NK}^{+} \mathrm{SCID}$, but without defects in hair and nails [34]. Both patients had low or absent naïve $\mathrm{T}$ cells. One of the patients had multiple infections and died of parainfluenza virus prior to one year of life. Separate compound heterozygous FOXN1 mutations were identified in the two patients [34].

\section{PAX1}

Paired Box 1 (PAX1) is a member of the paired box family of transcription factors that drive differentiation of tissues. In mice, expression of Paxl can be detected early in the
Genetic etiologies can be categorized by whether the impacted gene is involved in development of the entire midline region or more directly in thymic organ development

pharyngeal pouch endoderm, including the epithelium of the third pharyngeal pouch [35]. During thymus organogenesis, a large proportion of precursor and TECs express Paxl, however, this expression decreases over time, and adult mice have few cortical epithelial cells with significant Paxl expression [35]. These data support the hypothesis that PaxI expression in thymic epithelium plays a role in establishing the milieu for T cell maturation [35].

Several papers have described patients with mutations in PAX1 and autosomal recessive otofaciocervical syndrome type 2 (OTFCS2). Yamazaki et al. identified biallelic, loss-of-function $P A X 1$ mutations in six patients with OTFCS2 they described as linked to a syndromic form of SCID due to altered thymus development; two included patients were also previously described by Paganini et al. $[36,37]$. Patients typically had marked T cell lymphopenia. While the authors refer to these patients' immune dysfunction as SCID, it is likely congenital athymia given that the patients failed to develop $\mathrm{T}$ cells following successful engraftment of bone marrow transplantation and several 


\section{Early in development}

Newborn
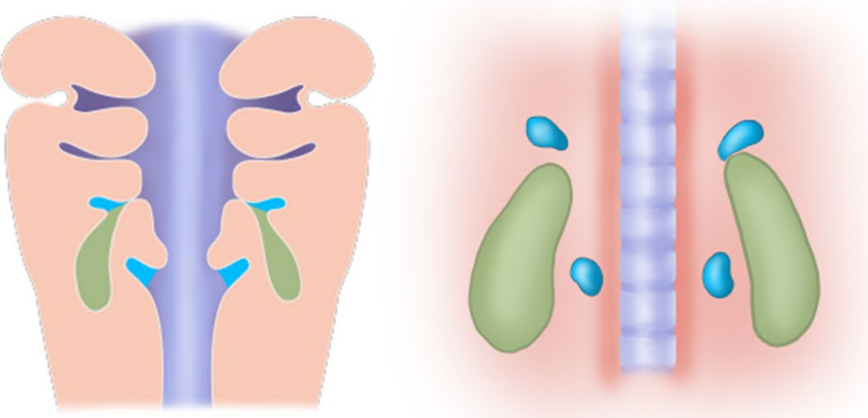

Key

Thymus

Parathyroid

Thyroid

Heart
Fig. 2 Normal thymus embryogenesis. Artistic rendering of the development of the thymus and parathyroid from the third pharyngeal pouch. Spatial and functional separation occurs early, with the thymus in the ventral posterior region and the parathyroid more anterior.

had documented absence of a thymic shadow on chest x-ray [36, 37]. Three separate biallelic PAX1 mutations were identified [37].
During development, the thymus migrates caudally and medially to its final position in the anterior part of the thorax and fuses with the developing thymus from the contralateral side

Patil et al. also described two siblings who presented with global developmental delay, hearing impairment, external ear malformations, and facial dysmorphism associated with

Table 1 Genes implicated in abnormal development of the thymus

\begin{tabular}{|c|c|c|c|}
\hline Gene & Role in thymus development & Associated conditions & $\begin{array}{l}\text { Non-immune manifestations of associated } \\
\text { conditions }\end{array}$ \\
\hline FOXN1 & $\begin{array}{l}\text { Development, differentiation, and maintenance } \\
\text { of thymic epithelial cells (TECs) in embry- } \\
\text { onic and postnatal life } \\
{[22-24,26]}\end{array}$ & $\begin{array}{l}\text { FOXN1 deficiency } \\
\text { (Nude/SCID) } \\
{[27]}\end{array}$ & Congenital alopecia and nail dystrophy \\
\hline$P A X 1$ & $\begin{array}{l}\text { Early expression in the pharyngeal pouches and } \\
\text { TECs [35] } \\
\text { Possible role in establishing milieu for T cell } \\
\text { maturation }\end{array}$ & $\begin{array}{l}\text { Otofaciocervical Syndrome Type } 2 \\
{[6,36]}\end{array}$ & $\begin{array}{l}\text { Facial dysmorphism, external ear anomalies, } \\
\text { hearing loss, branchial cysts or fistulas, } \\
\text { shoulder girdle anomalies, and mild intel- } \\
\text { lectual disability }\end{array}$ \\
\hline$T B X 1$ & $\begin{array}{l}\text { Pharyngeal arch artery formation and pharyn- } \\
\text { geal segmentation } \\
\text { Possible role in establishing parathyroid fate } \\
\text { [41-45] }\end{array}$ & $\begin{array}{l}\text { 22q11.2 Deletion Syndrome } \\
\text { DiGeorge Syndrome } \\
{[8]}\end{array}$ & $\begin{array}{l}\text { 22q11.2 Deletion Syndrome: Developmental } \\
\text { delay, ear anomalies and hearing loss, velo- } \\
\text { pharyngeal insufficiency, and cleft lip and/ } \\
\text { or palate } \\
\text { DiGeorge Syndrome: Congenital heart defects, } \\
\text { hypoparathyroidism }\end{array}$ \\
\hline CHD7 & $\begin{array}{l}\text { Pharyngeal arch artery and pouch formation } \\
\text { and TEC development }[47,48]\end{array}$ & $\begin{array}{l}\text { CHARGE Syndrome } \\
\text { [51] }\end{array}$ & $\begin{array}{l}\text { Eye coloboma, heart defects, choanal atresia, } \\
\text { retardation of growth and/or development, } \\
\text { genital abnormalities, and ear abnormalities } \\
\text { and/or deafness }\end{array}$ \\
\hline FOXI3 & Pharyngeal segmentation [105] & N/A & N/A \\
\hline$T B X 2$ & Role not well defined & N/A & N/A \\
\hline
\end{tabular}


OTFCS2. Exome sequencing revealed a homozygous $P A X 1$ mutation [6]. Both patients had a documented absent thymic shadow, but no further immune details were provided.

\section{Genetic Defects that Impact Development of the Entire Midline Region}

The most common genetic syndromes associated with defects in thymus development are 22q11.2 deletion syndrome and CHARGE syndrome. The genes implicated in these respective disorders, $T B X 1$ and $C H D 7$, play a role in development of the entire midline region, and as a result, patients with these syndromes present with a constellation of symptoms.

\section{2q11.2 Deletion and TBX1}

Among the genes that impact midline development generally, the most well-known association with immune deficiency is T-Box Transcription Factor 1 (TBX1). TBX1 is part of the approximately 30 genes in the $22 \mathrm{q} 11.2$ region that are commonly deleted in DGS [38-40]. TBXI belongs to the T-box family of transcription factors, a highly conserved group regulating vertebrate limb and heart development. The downstream targets of $T B X 1$ are not well understood. Starting early in embryogenesis in mice, $T b x l$ is expressed in the pharyngeal structure, including the endoderm and arch mesenchyme, and is thought to play a role in pharyngeal arch artery formation and pharyngeal segmentation [41-43]. Later in embryogenesis, expression of $T b x l$ in the third pharyngeal pouch becomes more restricted to the parathyroid domain [41, 44]. In fact, $T b x l$ expression may need to stop in order for TEC proliferation and differentiation to occur [45].

In humans, $T B X 1$ mutations and $T B X 1$ haploinsufficiency are thought to be the principal cause for the congenital defects associated with 22q11.2 deletion and DGS. A review of cDGS patients found that over $50 \%$ had 22q11.2 hemizygosity [5]. Most patients with 22q11.2 deletion syndrome have a 1.5-3 Mb deletion. Despite this, TBXI is the only gene that has been discovered to date to demonstrate a direct relationship between haploinsufficiency and replication of the 22q11.2 deletion syndrome and DGS phenotype [8]. Moreover, several mutations in TBXI's T-box binding domain have been shown in patients with the characteristic $22 \mathrm{q} 11.2$ deletion syndrome and DGS phenotype but lacking a 22q11.2 deletion [8]. Two mutations were identified in patients with conotruncal anomaly face syndrome/velocardiofacial syndrome, and one mutation in a patient with DGS and absent thymus; no further immune evaluations were performed.
In the mouse, $T b x 1$ has been shown to regulate proper development of the pharyngeal arch arteries in a gene dosage-dependent manner [38]. Tbxl $1^{ \pm}$embryos have defects of the fourth pharyngeal arch arteries, whereas $T b x I^{-/-}$embryos have developmental defects of the second, third, fourth, and sixth pharyngeal arches and arch arteries and the second, third, and fourth pharyngeal pouches [38, 39, 41]. Moreover, Tbx $1^{ \pm}$embryos do not demonstrate significant thymus abnormalities, whereas thymic aplasia is a characteristic feature of $T b x 1^{-1-}$ embryos $[39,46]$. Xu et al. demonstrated that the impact of $T b x l$ mutation on proper development of the mouse thymus also varies by the time point of its deletion. If Tbxl is deleted prior to E9.5 in development, then the thymus is absent. Whereas, if $T b x I$ is deleted at E9.5 or E10.5, a hypoplastic thymus forms, and if $T b x l$ is deleted after E11.5, there is no impact on thymus morphogenesis [42].

\section{CHD7}

Chromodomain Helicase DNA Binding Protein 7 (CHD7) is an ATP-dependent nucleosome remodeling factor. Randall et al. found that $C h d 7^{ \pm}$mouse embryos had defects in artery development of the fourth pharyngeal arch [47]. Approximately $11 \%$ of heterozygous $C h d 7^{ \pm}$embryos had a small or ectopically placed thymus at E14.5; this thymus hypoplasia correlated with downregulation of Foxn1 [47]. In zebrafish, $C h d 7$ has also been shown to play a role in TEC development from the pharyngeal endoderm and through downstream regulation of Foxnl [48].

CHD7 mutations have been implicated in CHARGE syndrome; approximately $60-65 \%$ of patients with CHARGE have a mutation in $C H D 7$ [49, 50]. Wong et al. reviewed the immunological aspects of CHARGE across multiple studies and found that thymic aplasia has been reported in 27 of 59 patients with CHARGE and in 16 of 36 patients with a proven variant in $C H D 7$. However, $\mathrm{T}$ cell evaluations were not consistently performed, and in some cases, thymic aplasia was documented only via imaging or surgery [51]. When patients with thymic aplasia did undergo immune evaluations, they typically demonstrated marked T cell lymphopenia, including reports of low naïve $\mathrm{T}$ cells, reduced $\mathrm{T}$ cell function, and normal B and NK cell numbers [52-57]. In addition, several patients without documented thymic aplasia or with severe hypoplasia had low naïve $\mathrm{T}$ cells or reported absence of T cells [58-60]. CHARGE has also been reported in patients with congenital athymia without genetic sequencing to confirm mutations in CHD7. Markert et al. reported association of cDGS and CHARGE in 14 of 54 patients undergoing evaluation for cultured thymus tissue implantation [5]. 


\section{TBX2 and FOXI3}

Other possible genes implicated in proper thymus development include $T B X 2$, and FOXI3. A recent study found that four individuals with clinical findings reminiscent of DGS, were heterozygous for $T B X 2$ variants; one family of three with the same genetic defect and a separate individual [61]. In the first family, all three members had abnormally low $\mathrm{T}$ cell numbers, and one required investigational cultured thymus tissue implantation. The fourth subject was from another family and did not have significant immune deficiency. Additionally, FOXI3 was recently implicated in a 22p11.2 microdeletion in several patients with features resembling DGS. These patients had T cell lymphopenia identified by low TRECs through newborn SCID screening and an inverted kappa/lambda ratio on flow cytometric analysis [62].

\section{Environmental Etiologies}

Several environmental etiologies are associated with congenital athymia. Diabetic embryopathy is associated with altered fetal thymus size, and other congenital abnormalities such as renal agenesis and butterfly vertebrae [63, 64]. Thymic aplasia has been demonstrated in infants of diabetic mothers, and Markert et al. found that $15 \%$ of patients undergoing evaluation for cultured thymus tissue implantation were born to mothers who had diabetes [5, 64]. The underlying mechanism is not well understood.

Fetal exposure to retinoic acid is also associated with a DGS phenotype, including thymus developmental abnormalities reported as thymic aplasia and ectopia, and hypoplasia $[13,65,66]$. A possible mechanism for the abnormalities in thymus development is alteration of Tbxl and/or Paxl expression by retinoic acid exposure [67, 68].

\section{Epidemiology of Congenital Athymia}

Congenital athymia is reported in the literature almost exclusively as a clinical feature of syndromic and genetic conditions. Since these reports often describe athymia associated with specific conditions, its overall incidence across all etiologies is not well understood. 22q11.2 deletion syndrome and CHARGE syndrome are the two most common genetic defects associated with thymic defects. The incidence of $22 q 11.2$ deletion is estimated at 1:4000-1:9700 live births, and the incidence of CHARGE is estimated at 1:8500 live births [69-72]. A subset of patients within these genetic disorders present with immunodeficiency, congenital heart defects, and hypoparathyroidism; they are described as having DGS. As mentioned in the foregoing, pDGS refers to patients with $\mathrm{T}$ cell deficiency but not athymia, whereas cDGS refers to patients with congenital athymia.

In published studies, congenital athymia is most commonly reported in the context of cDGS, with or without 22q11.2 genetic deletion [5, 73]. Recent widespread adoption of newborn screening for SCID in the USA has played a valuable role in helping to establish the incidence of cDGS; patients with congenital athymia are identified by a positive finding on a SCID screen due to absence of TRECs. Kwan et al. found that across 11 statewide newborn SCID screening programs, cDGS was diagnosed in 1:1,010,027 births [4]. Consistent with that estimate, the newborn SCID screening program in California (2010-2017) found that out of 3,252,156 reported births, cDGS was diagnosed in 1:813,039 births [74]. These low estimates underscore the advances in newborn screening in detecting congenital athymia.

In addition to cDGS, congenital athymia is also a hallmark of FOXN1 deficiency. Despite this, no precise incidence is known, and only approximately 10 cases of homozygous FOXN1 deficiency have been reported in the literature to date [7, 28-31]. Other underlying etiologies of congenital athymia do not have a well-established incidence in the literature.

\section{Diagnosis of Congenital Athymia}

Congenital athymia is often first identified through newborn screening for SCID (Fig. 3), which is required in all 50 states as of 2018 [3, 4, 74]. SCID screening evaluates immune function via quantification of TRECs by polymerase chain reaction using DNA isolated from dried blood spots [3, 74]. TRECs are episomal DNA excision products formed during $\mathrm{T}$ cell receptor rearrangement in the thymus [75]. Low or undetectable TRECs are considered a positive finding during SCID screening; reported cutoffs for a positive finding vary by state, ranging from fewer than 4 to 252 copies per microliter $(\mu \mathrm{L})[4,74]$. Patients with congenital athymia fall within the positive group.

All positive patients subsequently undergo complete and differential blood counts and lymphocyte phenotyping by flow cytometry [4, 62, 74]. Congenital athymia patients are identified by their profoundly low naïve T cells. Patients with congenital athymia will have less than 50 naïve T cells per cubic millimeter $\left(\mathrm{mm}^{3}\right)$ or naïve T cells comprising less than $5 \%$ of the total T cells $[5,14]$. Since patients with congenital athymia lack $\mathrm{T}$ cells but have normal numbers of $\mathrm{B}$ cells and NK cells, they present with a $\mathrm{T}^{-} \mathrm{B}^{+} \mathrm{NK}^{+}$phenotype. Complicating this, a subset of SCID patients also present with a $\mathrm{T}^{-} \mathrm{B}^{+} \mathrm{NK}^{+}$phenotype [76]. The initial approach to differentiate these patients is through known mutations in 


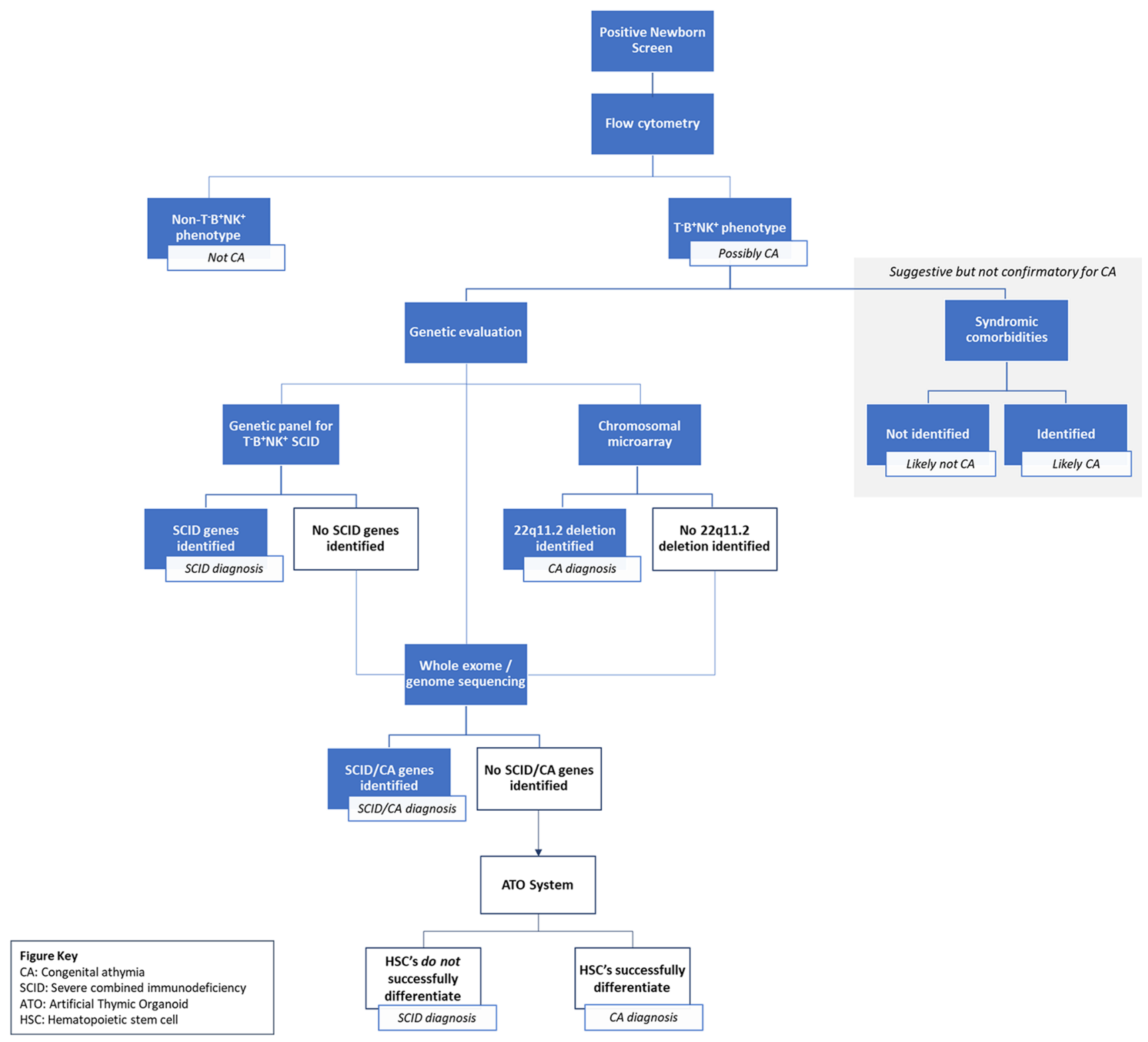

Fig. 3 Congenital athymia diagnostic pathway. Schematic of the diagnostic pathway for congenital athymia from initial identification through newborn screening to final diagnosis, including steps for how to accurately differentiate athymia from $\mathrm{T}^{-} \mathrm{B}^{+} \mathrm{NK}^{+} \mathrm{SCID}$

genes that cause athymia (described in the foregoing), or $\mathrm{T}^{-} \mathrm{B}^{+} \mathrm{NK}^{+} \mathrm{SCID}$, such as $I L-7 R$ and $C D 3 D$ [76]. A genetic panel for known $\mathrm{T}^{-} \mathrm{B}^{+} \mathrm{NK}^{+}$SCID gene mutations, whole exome or genome sequencing, and chromosomal microarray can be used to help differentiate these patients. If there are no SCID-causing genetic defects identified, and chromosomal microarray is not enlightening for syndromic defects, then proper diagnosis is challenging. Accurate identification of the underlying cause for immunodeficiency in these patients is critical for informed treatment decisions, i.e., receipt of hematopoietic stem cell transplant versus cultured thymus tissue implantation. Seet et al. recently developed an artificial thymic organoid (ATO) system that supports in vitro differentiation, positive selection, and maturation of human $\mathrm{T}$ cells from cord blood, bone marrow, and/or peripheral blood CD $34^{+}$hematopoietic stem cells, dependent on the collaborating organization [77-79]. This system can evaluate the ability of hematopoietic cells to become mature $\mathrm{T}$ cells, such that if the isolated cells are able to differentiate appropriately, a diagnosis of SCID can be excluded.

Patients can also be evaluated for comorbidities that may reveal athymia as part of a clinical picture of a syndromic condition, such as cDGS or CHARGE. While a positive finding of a syndromic comorbidity may indicate congenital athymia versus SCID, it should not be used to establish a definitive diagnosis without an additional confirmatory 
method. Of note, although confirmation of congenital athymia has been reported in the literature through imaging studies (i.e. chest X-ray [33]), complete absence of the thymus must be confirmed in patients based on laboratory findings. Imaging can fail to determine the presence of a thymus in the mediastinum as it may be small and easily missed, or it may not have descended properly [80].

Subsequent testing in patients with suspected congenital athymia may include a mitogen $\mathrm{T}$ cell proliferation assay via flow cytometry, which is available at specialized immune diagnostic laboratories and requires only a small blood volume. Mitogen T cell proliferation assay is frequently sent as part of the initial diagnosis of $\mathrm{T}$ cell lymphopenia; these tests use phytohemagglutinin or concanavalin A to stimulate $\mathrm{T}$ cell responses independently of antigen specificity. In general, patients with congenital athymia have low mitogen stimulation, typically less than 20 -fold proliferative response, like patients with SCID [2, 81]. However, in the face of oligoclonal $\mathrm{T}$ cell expansion and autologous GVHD, patients with congenital athymia may demonstrate responses to mitogens [15].

Some patients with congenital athymia may develop high numbers of circulating $\mathrm{T}$ cells and can demonstrate a response to mitogens. These patients are uniquely characterized by a rash and associated lymphadenopathy $[15,30,82$, 83]. Biopsy of the rash reveals features of an inflammatory response in the stratum corneum, epidermis, and dermis, including infiltrating $\mathrm{T}$ cells, exocytosis, parakeratosis, and spongiosis [83]. This phenotype develops at some point after birth [18]. The last published breakdown between typical and atypical phenotype was in 2009 and noted that $30 \%$ of patients had an atypical phenotype [14]. We expect that the percent of atypical patients has increased overtime due to widespread newborn screening and the institution of supportive care shortly after birth. These advances in early diagnosis and isolation have allowed patients to live longer, likely increasing the proportion of patients transitioning to the atypical phenotype [3]. The high numbers of circulating $\mathrm{T}$ cells in these patients are oligoclonal (clonal expansions of $\mathrm{T}$ cells expressing similar $\mathrm{T}$ cell receptor variable regions) and lack expression of naïve $\mathrm{T}$ cell markers (including, CD45RA, CD62L, and CD31) [15]. These T cells have been shown to develop through extrathymic proliferation and display a predominantly memory phenotype, expressing $\mathrm{T}$ cell marker CD45RO [30, 37, 84-86]. A finding of significant CD45RO ${ }^{+} \mathrm{T}$ cells by flow cytometry in athymic infants is an indicator for this atypical phenotype. Possible further evaluation of $T$ cells in these patients may include $T$ cell receptor $\beta$ chain variable repertoire analysis by flow cytometry or spectratyping to establish their oligoclonality [15]. Additionally, although these $\mathrm{T}$ cells may functionally proliferate after stimulation with mitogens, they do not respond to antigens and therefore are not protective against infection [15]. Notably, the presenting atypical phenotype can appear similar to Omenn syndrome secondary to SCID and maternal engraftment $[87,88]$. Chimerism studies can be used to distinguish maternal engraftment versus Omenn syndrome, whereas autologous GVHD and Omenn syndrome appear immunologically the same.

Patients with suspected or confirmed congenital athymia should undergo testing to identify possible associated genetic and syndromic conditions. Genetic testing and chromosomal microarray can help to identify conditions such as 22q11.2 deletion syndrome (22q11.2 hemizygosity), CHARGE ( $C H D 7$ mutations), or FOXN1 deficiency (FOXN1 mutations). Patients should also be evaluated for clinical manifestations of associated conditions (described in Table 1).

\section{Clinical Manifestations of Congenital Athymia}

The clinical manifestations of congenital athymia are a direct result of the absence of the thymus and the inability to produce immunocompetent $\mathrm{T}$ cells. Two fundamental categories describe the clinical features of the disease: profound $\mathrm{T}$ cell immunodeficiency and autologous GVHD. As congenital athymia is often a feature of broader syndromic or genetic conditions, patients can present with a constellation of symptoms.

\section{Infections}

Prior to widespread availability of newborn screening, patients with congenital athymia presented in the first few months of life with recurrent and persistent infections, often categorized as severe $[2,16,51,82,89]$. T cell immunodeficiency leads to an increased susceptibility to bacterial, viral, and fungal infections. Pneumonias occur at a particularly high rate in these patients $[16,82,89]$. One multicenter survey of patients with congenital athymia found that $~ 30 \%$ of patients developed pneumonia [16]. These pneumonias were caused by Pseudomonas spp including $P$. aerugi$n o s a$, as well as $C$. albicans, $S$. aureus, $S$. pneumoniae, and Haemophilus parainfluenza. Pneumonias can be recurrent and severe and patients can develop chronic lung disease $[16,82,89]$. Other severe pulmonary infections have been reported with respiratory syncytial virus and M. bovis [7, $82,89]$. Gastrointestinal infections are also frequent among this population, including rotavirus, norovirus, enterovirus, $M$. bovis, and $C$. difficile infections [7, 16, 82, 89]. These infections can lead to failure to thrive, malabsorption, and diarrhea. While infections are most commonly reported in 
pulmonary and gastrointestinal organs, patients with congenital athymia can present with a myriad of other infection types. Infections of the urinary tract from K. pnuemoniae, $E$. faecium, and echovirus have been reported, as well as infections of the head, ears, nose, and throat including meningitis, sinusitis, mastoiditis, and thrush [16, 82, 89]. Of particular note, athymic patients also experience sepsis, which can be associated with mortality in this patient population $[16,81$, $82,89,90]$.

The profound nature of the $\mathrm{T}$ cell immunodeficiency in patients who lack a thymus also puts them at significant risk from life-threatening opportunistic infections, including Cytomegalovirus (CMV), Candida, Pneumocystis Carinii and Human Herpesvirus 6 infections [7, 16, 81, 82, 89, 91]. $\mathrm{CMV}$ infection is of particular concern, leading clinicians to recommend that mothers of infants with primary immunodeficiencies not breastfeed to prevent potential CMV transmission to the infant [92-94]. CMV infection is an important consideration for eligibility for cultured thymus tissue implantation, as CMV infections have been reported to be fatal in these infants [18].

\section{Autologous GVHD}

Potentially the most challenging aspect of managing patients with congenital athymia is their propensity to develop inflammatory autoimmune conditions, as described in the foregoing as autologous GVHD. In congenital athymia, T cells can undergo extrathymic oligoclonal expansion. These cells confer little to no protective immunity and can infiltrate organs causing autologous GVHD. Patients with oligoclonal T cell expansion typically have a characteristic eczematous rash and associated lymphadenopathy. Infiltrating $\mathrm{T}$ cells can cause transaminitis, and enteropathy in the gastrointestinal system [14]. Autologous GVHD contributes to increased morbidity in these patients, leading to higher susceptibility to infections. Treatment for these patients involves immunosuppression typically with steroids or calcineurin inhibitors, with accompanying potential adverse events such as hypertension, renal complications, and thrombocytopenia $[14,82]$.

\section{Autoimmunity}

In addition to autologous GVHD, patients with congenital athymia have other manifestations of autoimmune mediated processes, such as hypothyroidism, autoimmune thyroiditis, and Coombs-positive hemolytic anemia $[16,89,90]$. These autoimmune processes have also been described in patients with $22 \mathrm{q} 11.2$ deletion syndrome without congenital athymia and include rheumatoid arthritis, idiopathic thrombocytopenia, hemolytic anemia, and thyroid disease [95].

\section{Treatment of Patients With Congenital Athymia}

\section{Isolation}

Management of patients with congenital athymia focuses on supportive care to reduce the risk of infection until the underlying immune deficiency can be corrected. Similar to other primary immunodeficiencies, as soon as congenital athymia is suspected after birth, it is recommended that neonates in the hospital be placed in reverse isolation with air filtering systems such as high-efficiency particulate air (HEPA) and positive pressure laminar air flow (LAF), though isolation protocols vary by hospital [27, 94, 96, 97]. All visitors are required to follow strict infectious disease prevention measures such as surgical hand washing protocols, hair covers, masks, shoe covers, sterile gowns and gloves [93, 94, 97]. If an athymic patient is discharged, isolation and hygiene procedures must also be maintained at home. This includes frequent handwashing, changing clothes/sanitizing upon re-entering the house, and restricting visitors in the home.

\section{Prophylaxis}

In addition to isolation, patients with congenital athymia should begin antimicrobial prophylaxis to prevent bacterial, viral and fungal infections [18, 93, 94]. During this time, patients are closely monitored and treated for all infections.

\section{Immunoglobulin}

Although patients with congenital athymia often have normal numbers of B cells, their B cell function is usually reduced. Therefore, patients should receive immunoglobulin replacement $[5,18,94]$.

\section{Vaccination Avoidance}

Recommendations for vaccine eligibility depend on the extent of the patient's immunodeficiency [98]. Patients with partial T cell deficiency, such as pDGS, may be able to receive select live vaccines, based on their degree of immunodeficiency and $\mathrm{T}$ cell function; in general, retrospective studies have supported their safety in pDGS [99, 100]. For patients with complete $T$ cell deficiency, such as congenital athymia associated with cDGS, all live vaccines 
are contraindicated [98]. Moreover, it is likely that all vaccines in athymic patients are ineffective prior to thymic implantation due to the importance of $\mathrm{T}$ cell help in directing appropriate antibody responses.

\section{Blood Products}

All blood products given to the patient should be irradiated to prevent GVHD and tested and confirmed seronegative for CMV [5, 93, 96].

\section{Immunosuppression}

Patients with oligoclonal T cells and/or elevated proliferative responsiveness to mitogens should also receive immunosuppression (such as steroids or calcineurin inhibitors) to manage their inflammatory reaction and reduce the risk of autologous GVHD [18, 82]. In addition, they may require anti-thymocyte globulin prior to receiving a cultured thymus tissue implantation.

\section{Syndromic Comorbidities}

Though not directly related to their immunodeficiency, patients with congenital athymia also require management for defects due to associated syndromic conditions. Approximately $80 \%$ of patients with cDGS require calcium supplementation due to coexisting hypoparathyroidism that may manifest as newborn seizures [5]. This treatment needs to be monitored closely as severe hypocalcemia can lead to cardiac arrest and seizures, and supplementation can lead to nephrocalcinosis [2, 90]. Patients with congenital athymia as part of a cDGS clinical picture often require surgical care for heart defects [5]. cDGS patients may require tracheostomy for laryngomalacia, tracheomalacia, or ventilator-dependence secondary to cardiac problems [90]. Central lines for venous access and feeding tubes for nutritional supplementation are commonly required. [90]. Pediatric specialties involved in the care of these patients include neonatology, immunology, cardiology, endocrinology, nephrology, genetics, rheumatology, and hematology.

\section{Hematopoietic Stem Cell Transplant}

Hematopoietic stem cell transplant (HSCT) has been performed in congenital athymia patients with relatively little success [16, 17]. Survival after HSCT in patients with congenital athymia is low compared to patients with SCID (41\% compared to as high as $90 \%$, respectively) $[16,101,102]$. Moreover, significant adverse events have been reported in athymic patients post-HSCT, including GVHD in $\sim 50 \%$ of patients [16]. Immune reconstitution in athymic patients post-HSCT is also poor, with no clear evidence of successful regeneration of naïve T cells [16].

\section{Cultured Thymus Tissue Implantation}

Establishing a functional thymic environment is essential to achieving full immune reconstitution in patients with congenital athymia. Cultured thymus tissue implantation (CTTI), historically described as thymus transplantation, has been shown in clinical trials to restore a functional $\mathrm{T}$ cell compartment via the migration of the recipient's bone marrow derived stem cells to the implanted cultured thymus tissue, followed by subsequent development of immunocompetent naïve T cells [14, 18]. CTTI is currently being investigated in the USA by Dr. Louise Markert at Duke University [18] and has been performed in patients with cDGS, FOXN1 deficiency, and associated genetic and syndromic conditions including 22q11.2 hemizygosity, CHARGE, and diabetic embryopathy $[5,7]$. The investigational use of cultured thymus tissue implantation has been previously described in detail $[14,18]$.

In the clinical trials of CTTI, patients were closely monitored post-implantation as full immune reconstitution took many months. Prior to reconstitution, patients were maintained in isolation and continued to receive immunoglobulin replacement and prophylactic antimicrobials. Criteria were developed to define the stepwise immune reconstitution and corresponding tapering of supportive care in these patients [18]. If patients were on immunosuppressive drugs prior to implantation, they were weaned from immunosuppression when naïve $\mathrm{T}$ cells were greater than $10 \%$ of the total $\mathrm{T}$ cell count [18]. Circulating naïve $T$ cells were typically detected in patients approximately 6 months post-implantation, and peaked around 1-2 years post-implantation [14, 18]. Once patients were successfully weaned from immunosuppressive drugs, were 9 months post-implantation, had normal trough IgG levels for age, and demonstrated a proliferative response to mitogens of at least 100,000 counts per minute, immunoglobulin replacement therapy was discontinued [18]. Patients typically developed a normal proliferative response to mitogens 9-12 months post-implantation, while B cell function normalized 1-2 years post-implantation [14, 18]. Biopsies 2-3 months post-implantation demonstrated thymopoiesis in approximately $80 \%$ of patients, and all surviving patients with thymopoiesis on biopsy developed naïve $\mathrm{T}$ cells and adequate $\mathrm{T}$ cell function [103].

The efficacy and safety of CTTI was last reported in the peer reviewed literature in 2010 [18]. Since that time, there has been a significant expansion of the clinical trial program at Duke from 60 subjects reported in 2010 to 105 subjects in 2021 [104]. The results of this clinical trial 
update are not available at the time of this publication. The 2010 report noted that survival post-implantation was $72 \%$ across 60 patients [18]. Post-implant mortality most often occurred in patients prior to full immune reconstitution; 2 patients died more than one-year post-implant [18]. Survival curves show that the death rate diminishes 6-12 months post-implantation when immune reconstitution would be expected to be achieved [5, 14, 18]. Across the 60 patients reported in 2010 , the majority of deaths were a result of infections, most commonly viral [18]. While infections were one of the most common adverse events post-implantation, autoimmune disorders were also reported. Thyroid disease has been reported in 13 patients following implantation [18]. As a result, patients undergo thyroid function evaluation periodically [18]. Cytopenias and other autoimmune conditions have also been reported post-implant [18]. It is unclear if autoimmune disease is a function of the underlying congenital athymia or secondary to the immune reconstitution.

\section{Conclusions}

Congenital athymia is characterized by profound immunodeficiency due to the absence of a functioning thymus. The two primary manifestations of this disease are a result of the inability to produce immunocompetent $T$ cells, leading both to immunodeficiency characterized by increased susceptibility to infection, and extrathymic $\mathrm{T}$ cell production leading to autologous GVHD. These patients can also present with additional symptoms related to associated genetic or syndromic conditions (FOXN1 deficiency, 22q11.2 deletion, CHARGE, and cDGS). Despite the currently available literature on congenital athymia, gaps remain, particularly in the full understanding of the etiology of congenital athymia. Future work should focus on improving the clinical management and treatment options available to patients with congenital athymia.

Acknowledgements We thank Dr. John W. Sleasman (Chief, Division of Allergy, Immunology, and Pulmonary Medicine, Department of Pediatrics, Duke University School of Medicine) for providing a thoughtful review of the manuscript and helping us to critically revise the article for intellectual content. We also thank Matt O'Hara, MBA (Trinity Life Sciences) for his review of the manuscript.

Author Contribution CC, ES, AS, and SK wrote the manuscript. CC and $\mathrm{EH}$ conceived the structure of this review. SK and EH edited the manuscript and provided conceptual guidance.

Data Availability Not applicable.

\section{Declarations}

Ethics Approval and Consent to Participate Not applicable.
Consent for Publication All authors of this manuscript attest that we have all reviewed this manuscript and have contributed in a substantive and intellectual manner to the work described.

Competing Interests Cathleen Collins, Emily Sharpe, Abigail Silber and Elena Hsieh receive consulting fees from Enzyvant Therapeutics. Sarah Kulke is Vice President of Medical Affairs at Enzyvant Therapeutics (since May 2020) and therefore receives salary, annual performance bonus, and cash based long term incentive program.

Open Access This article is licensed under a Creative Commons Attribution 4.0 International License, which permits use, sharing, adaptation, distribution and reproduction in any medium or format, as long as you give appropriate credit to the original author(s) and the source, provide a link to the Creative Commons licence, and indicate if changes were made. The images or other third party material in this article are included in the article's Creative Commons licence, unless indicated otherwise in a credit line to the material. If material is not included in the article's Creative Commons licence and your intended use is not permitted by statutory regulation or exceeds the permitted use, you will need to obtain permission directly from the copyright holder. To view a copy of this licence, visit http://creativecommons.org/licenses/by/4.0/.

\section{References}

1. Regulation (EU) No 536/2014 of the European Parliament and of the Council of 16 April 2014 on clinical trials on medicinal products for human use, and repealing Directive 2001/20/EC (2014).

2. Markert ML, Hummell DS, Rosenblatt HM, Schiff SE, Harville TO, Williams LW, et al. Complete DiGeorge syndrome: persistence of profound immunodeficiency. J Pediatr. 1998;132(1):15-21. https://doi.org/10.1016/s0022-3476(98) 70478-0.

3. van der Burg M, Mahlaoui N, Gaspar HB, Pai SY. Universal newborn screening for severe combined Immunodeficiency (SCID). Front Pediatr. 2019;7:373. https://doi.org/10.3389/ fped.2019.00373.

4. Kwan A, Abraham RS, Currier R, Brower A, Andruszewski $\mathrm{K}$, Abbott JK, et al. Newborn screening for severe combined immunodeficiency in 11 screening programs in the United States. JAMA. 2014;312(7):729-38. https://doi.org/10.1001/ jama.2014.9132.

5. Markert ML, Devlin BH, Alexieff MJ, Li J, McCarthy EA, Gupton SE, et al. Review of 54 patients with complete DiGeorge anomaly enrolled in protocols for thymus transplantation: outcome of 44 consecutive transplants. Blood. 2007;109(10):4539-47. https://doi.org/10.1182/ blood-2006-10-048652.

6. Patil SJ, Das Bhowmik A, Bhat V, Satidevi Vineeth V, Vasudevamurthy R, Dalal A. Autosomal recessive otofaciocervical syndrome type 2 with novel homozygous small insertion in PAX1 gene. Am J Med Genet A. 2018;176(5):1200-6. https://doi.org/ 10.1002/ajmg.a.38659.

7. Markert ML, Marques JG, Neven B, Devlin BH, McCarthy EA, Chinn IK, et al. First use of thymus transplantation therapy for FOXN1 deficiency (nude/SCID): a report of 2 cases. Blood. 2011;117(2):688-96. https://doi.org/10.1182/ blood-2010-06-292490.

8. Yagi H, Furutani Y, Hamada H, Sasaki T, Asakawa S, Minoshima $\mathrm{S}$, et al. Role of TBX1 in human del22q11.2 syndrome. 
Lancet. 2003;362(9393):1366-73. https://doi.org/10.1016/s01406736(03)14632-6.

9. Chinen J, Rosenblatt HM, Smith EO, Shearer WT, Noroski LM. Long-term assessment of T-cell populations in DiGeorge syndrome. J Allergy Clin Immunol. 2003;111(3):573-9. https://doi. org/10.1067/mai.2003.165.

10. Hong R. The DiGeorge anomaly. Clin Rev Allergy Immunol. 2001;20(1):43-60. https://doi.org/10.1385/CRIAI:20:1:43.

11. Ryan AK, Goodship JA, Wilson DI, Philip N, Levy A, Seidel $\mathrm{H}$, et al. Spectrum of clinical features associated with interstitial chromosome 22q11 deletions: a European collaborative study. J Med Genet. 1997;34(10):798-804. https://doi.org/10.1136/jmg. 34.10.798.

12. Muller W, Peter HH, Wilken M, Juppner H, Kallfelz HC, Krohn HP, et al. The DiGeorge syndrome. I. Clinical evaluation and course of partial and complete forms of the syndrome. Eur $\mathbf{J}$ Pediatr. 1988;147(5):496-502. https://doi.org/10.1007/BF004 41974.

13. Lammer EJ, Chen DT, Hoar RM, Agnish ND, Benke PJ, Braun JT, et al. Retinoic acid embryopathy. N Engl J Med. 1985;313(14):837-41. https://doi.org/10.1056/NEJM198510 033131401 .

14. Markert ML, Devlin BH, Chinn IK, McCarthy EA. Thymus transplantation in complete DiGeorge anomaly. Immunol Res. 2009;44(1-3):61-70. https://doi.org/10.1007/ s12026-008-8082-5.

15. Markert ML, Alexieff MJ, Li J, Sarzotti M, Ozaki DA, Devlin $\mathrm{BH}$, et al. Complete DiGeorge syndrome: development of rash, lymphadenopathy, and oligoclonal $\mathrm{T}$ cells in 5 cases. J Allergy Clin Immunol. 2004;113(4):734-41. https://doi.org/10.1016/j. jaci.2004.01.766.

16. Janda A, Sedlacek P, Honig M, Friedrich W, Champagne M, Matsumoto T, et al. Multicenter survey on the outcome of transplantation of hematopoietic cells in patients with the complete form of DiGeorge anomaly. Blood. 2010;116(13):2229-36. https://doi. org/10.1182/blood-2010-03-275966.

17. Pignata C, Gaetaniello L, Masci AM, Frank J, Christiano A, Matrecano E, et al. Human equivalent of the mouse Nude/SCID phenotype: long-term evaluation of immunologic reconstitution after bone marrow transplantation. Blood. 2001;97(4):880-5. https://doi.org/10.1182/blood.v97.4.880.

18. Markert ML, Devlin BH, McCarthy EA. Thymus transplantation. Clin Immunol. 2010;135(2):236-46. https://doi.org/10.1016/j. clim.2010.02.007.

19. Gordon J, Manley NR. Mechanisms of thymus organogenesis and morphogenesis. Development. 2011;138(18):3865-78. https:// doi.org/10.1242/dev.059998.

20. Dzhagalov I, Phee H. How to find your way through the thymus: a practical guide for aspiring T cells. Cell Mol Life Sci. 2012;69(5):663-82. https://doi.org/10.1007/s00018-011-0791-6.

21. Alexandropoulos K, Danzl NM. Thymic epithelial cells: antigen presenting cells that regulate $\mathrm{T}$ cell repertoire and tolerance development. Immunol Res. 2012;54(1-3):177-90. https://doi. org/10.1007/s12026-012-8301-y.

22. Blackburn CC, Augustine CL, Li R, Harvey RP, Malin MA, Boyd $\mathrm{RL}$, et al. The nu gene acts cell-autonomously and is required for differentiation of thymic epithelial progenitors. Proc Natl Acad Sci U S A. 1996;93(12):5742-6. https://doi.org/10.1073/pnas. 93.12.5742.

23. Nowell CS, Bredenkamp N, Tetelin S, Jin X, Tischner C, Vaidya $\mathrm{H}$, et al. Foxn 1 regulates lineage progression in cortical and medullary thymic epithelial cells but is dispensable for medullary sublineage divergence. PLoS Genet. 2011;7(11):e1002348. https://doi.org/10.1371/journal.pgen.1002348.

24. Zuklys S, Handel A, Zhanybekova S, Govani F, Keller M, Maio $\mathrm{S}$, et al. Foxn1 regulates key target genes essential for $\mathrm{T}$ cell development in postnatal thymic epithelial cells. Nat Immunol. 2016;17(10):1206-15. https://doi.org/10.1038/ni.3537.

25. Brissette JL, Li J, Kamimura J, Lee D, Dotto GP. The product of the mouse nude locus, Whn, regulates the balance between epithelial cell growth and differentiation. Genes Dev. 1996;10(17):2212-21. https://doi.org/10.1101/gad.10.17.2212.

26. Cheng L, Guo J, Sun L, Fu J, Barnes PF, Metzger D, et al. Postnatal tissue-specific disruption of transcription factor FoxN1 triggers acute thymic atrophy. J Biol Chem. 2010;285(8):5836-47. https://doi.org/10.1074/jbc.M109.072124.

27. Rota IA, Dhalla F. FOXN1 deficient nude severe combined immunodeficiency. Orphanet J Rare Dis. 2017;12(1):6. https:// doi.org/10.1186/s13023-016-0557-1.

28. Pignata C, Fiore M, Guzzetta V, Castaldo A, Sebastio G, Porta $\mathrm{F}$, et al. Congenital alopecia and nail dystrophy associated with severe functional T-cell immunodeficiency in two sibs. Am J Med Genet. 1996;65(2):167-70. https://doi.org/10.1002/(SICI) 1096-8628(19961016)65:2\%3c167::AID-AJMG17\%3e3.0. $\mathrm{CO} ; 2-\mathrm{O}$.

29. Adriani M, Martinez-Mir A, Fusco F, Busiello R, Frank J, Telese $\mathrm{S}$, et al. Ancestral founder mutation of the nude (FOXN1) gene in congenital severe combined immunodeficiency associated with alopecia in southern Italy population. Ann Hum Genet. 2004;68(Pt 3):265-8. https://doi.org/10.1046/j.1529-8817.2004. 00091.x.

30. Chou J, Massaad MJ, Wakim RH, Bainter W, Dbaibo G, Geha RS. A novel mutation in FOXN1 resulting in SCID: a case report and literature review. Clin Immunol. 2014;155(1):30-2. https:// doi.org/10.1016/j.clim.2014.08.005.

31. Radha Rama Devi A, Panday NN, Naushad SM. FOXN1 Italian founder mutation in Indian family: implications in prenatal diagnosis. Gene. 2017;627:222-5. https://doi.org/10.1016/j.gene. 2017.06.033.

32. Auricchio L, Adriani M, Frank J, Busiello R, Christiano A, Pignata $\mathrm{C}$. Nail dystrophy associated with a heterozygous mutation of the nude/SCID human FOXN1 (WHN) gene. Arch Dermatol. 2005;141(5):647-8. https://doi.org/10.1001/archderm.141.5.647.

33. Bosticardo M, Yamazaki Y, Cowan J, Giardino G, Corsino C, Scalia G, et al. Heterozygous FOXN1 variants cause low TRECs and severe $\mathrm{T}$ cell lymphopenia, revealing a crucial role of FOXN1 in supporting early thymopoiesis. Am J Hum Genet. 2019;105(3):549-61. https://doi.org/10.1016/j.ajhg.2019.07. 014.

34. Du Q, Huynh LK, Coskun F, Molina E, King MA, Raj P, et al. FOXN1 compound heterozygous mutations cause selective thymic hypoplasia in humans. J Clin Invest. 2019;129(11):472438. https://doi.org/10.1172/JCI127565.

35. Wallin J, Eibel H, Neubuser A, Wilting J, Koseki H, Balling R. Pax 1 is expressed during development of the thymus epithelium and is required for normal T-cell maturation. Development. 1996;122(1):23-30.

36. Paganini I, Sestini R, Capone GL, Putignano AL, Contini E, Giotti I, et al. A novel PAX1 null homozygous mutation in autosomal recessive otofaciocervical syndrome associated with severe combined immunodeficiency. Clin Genet. 2017;92(6):664-8. https:// doi.org/10.1111/cge.13085.

37. Yamazaki Y, Urrutia R, Franco LM, Giliani S, Zhang K, Alazami AM et al. PAX1 is essential for development and function of the human thymus. Sci Immunol. 2020;5(44). https://doi.org/10. 1126/sciimmunol.aax1036.

38. Lindsay EA, Vitelli F, Su H, Morishima M, Huynh T, Pramparo $\mathrm{T}$, et al. Tbx 1 haploinsufficieny in the DiGeorge syndrome region causes aortic arch defects in mice. Nature. 2001;410(6824):97101. https://doi.org/10.1038/35065105. 
39. Jerome LA, Papaioannou VE. DiGeorge syndrome phenotype in mice mutant for the T-box gene, Tbx1. Nat Genet. 2001;27(3):286-91. https://doi.org/10.1038/85845.

40. Chieffo C, Garvey N, Gong W, Roe B, Zhang G, Silver L, et al. Isolation and characterization of a gene from the DiGeorge chromosomal region homologous to the mouse Tbx 1 gene. Genomics. 1997;43(3):267-77. https://doi.org/10.1006/geno.1997.4829.

41. Vitelli F, Morishima M, Taddei I, Lindsay EA, Baldini A. Tbx1 mutation causes multiple cardiovascular defects and disrupts neural crest and cranial nerve migratory pathways. Hum Mol Genet. 2002;11(8):915-22. https://doi.org/10.1093/hmg/11.8. 915.

42. Xu H, Cerrato F, Baldini A. Timed mutation and cell-fate mapping reveal reiterated roles of Tbx 1 during embryogenesis, and a crucial function during segmentation of the pharyngeal system via regulation of endoderm expansion. Development. 2005;132(19):4387-95. https://doi.org/10.1242/dev.02018.

43. Chapman DL, Garvey N, Hancock S, Alexiou M, Agulnik SI, Gibson-Brown JJ, et al. Expression of the T-box family genes, Tbx1-Tbx5, during early mouse development. Dev Dyn. 1996;206(4):379-90. https://doi.org/10.1002/(SICI)10970177(199608)206:4\%3c379::AID-AJA4\%3e3.0.CO;2-F.

44. Manley NR, Selleri L, Brendolan A, Gordon J, Cleary ML. Abnormalities of caudal pharyngeal pouch development in Pbx1 knockout mice mimic loss of Hox3 paralogs. Dev Biol. 2004;276(2):301-12. https://doi.org/10.1016/j.ydbio.2004.08. 030.

45. Reeh KA, Cardenas KT, Bain VE, Liu Z, Laurent M, Manley NR, et al. Ectopic TBX1 suppresses thymic epithelial cell differentiation and proliferation during thymus organogenesis. Development. 2014;141(15):2950-8. https://doi.org/10.1242/dev.111641.

46. Liao J, Kochilas L, Nowotschin S, Arnold JS, Aggarwal VS, Epstein JA, et al. Full spectrum of malformations in velo-cardiofacial syndrome/DiGeorge syndrome mouse models by altering Tbx1 dosage. Hum Mol Genet. 2004;13(15):1577-85. https:// doi.org/10.1093/hmg/ddh176.

47. Randall V, McCue K, Roberts C, Kyriakopoulou V, Beddow S, Barrett AN, et al. Great vessel development requires biallelic expression of Chd7 and Tbx1 in pharyngeal ectoderm in mice. J Clin Invest. 2009;119(11):3301-10. https://doi.org/10.1172/ JCI37561.

48. Liu ZZ, Wang ZL, Choi TI, Huang WT, Wang HT, Han YY, et al. Chd7 is critical for early T-cell development and thymus organogenesis in zebrafish. Am J Pathol. 2018;188(4):104358. https://doi.org/10.1016/j.ajpath.2017.12.005.

49. Jongmans MC, Admiraal RJ, van der Donk KP, Vissers LE, Baas AF, Kapusta L, et al. CHARGE syndrome: the phenotypic spectrum of mutations in the CHD7 gene. J Med Genet. 2006;43(4):306-14. https://doi.org/10.1136/jmg.2005.036061.

50. Lalani SR, Safiullah AM, Fernbach SD, Harutyunyan KG, Thaller C, Peterson LE, et al. Spectrum of CHD7 mutations in 110 individuals with CHARGE syndrome and genotypephenotype correlation. Am J Hum Genet. 2006;78(2):303-14. https://doi.org/10.1086/500273.

51. Wong MT, Scholvinck EH, Lambeck AJ, van RavenswaaijArts CM. CHARGE syndrome: a review of the immunological aspects. Eur J Hum Genet. 2015;23(11):1451-9. https://doi. org/10.1038/ejhg.2015.7.

52. Assing K, Nielsen C, Kirchhoff M, Madsen HO, Ryder LP, Fisker N. CD4+ CD31+ recent thymic emigrants in CHD7 haploinsufficiency (CHARGE syndrome): a case. Hum Immunol. 2013;74(9):1047-50. https://doi.org/10.1016/j.humimm. 2013.06.002.

53. Chopra C, Baretto R, Duddridge M, Browning MJ. T-cell immunodeficiency in CHARGE syndrome. Acta Paediatr.
2009;98(2):408-10. https://doi.org/10.1111/j.1651-2227.2008. 01077.x.

54. Gennery AR, Slatter MA, Rice J, Hoefsloot LH, Barge D, McLean-Tooke A, et al. Mutations in CHD7 in patients with CHARGE syndrome cause T-B + natural killer cell + severe combined immune deficiency and may cause Omenn-like syndrome. Clin Exp Immunol. 2008;153(1):75-80. https://doi.org/ 10.1111/j.1365-2249.2008.03681.x.

55. Hoover-Fong J, Savage WJ, Lisi E, Winkelstein J, Thomas GH, Hoefsloot LH, et al. Congenital T cell deficiency in a patient with CHARGE syndrome. J Pediatr. 2009;154(1):140-2. https://doi.org/10.1016/j.jpeds.2008.07.049.

56. Inoue $\mathrm{H}$, Takada $\mathrm{H}$, Kusuda $\mathrm{T}$, Goto $\mathrm{T}$, Ochiai M, Kinjo $\mathrm{T}$, et al. Successful cord blood transplantation for a CHARGE syndrome with CHD7 mutation showing DiGeorge sequence including hypoparathyroidism. Eur J Pediatr. 2010;169(7):839 44. https://doi.org/10.1007/s00431-009-1126-6.

57. Kaliakatsos M, Giannakopoulos A, Fryssira H, Kanariou M, Skiathitou AV, Siahanidou T, et al. Combined microdeletions and CHD7 mutation causing severe CHARGE/DiGeorge syndrome: clinical presentation and molecular investigation by array-CGH. J Hum Genet. 2010;55(11):761-3. https://doi.org/ 10.1038/jhg.2010.95.

58. Sanka M, Tangsinmankong N, Loscalzo M, Sleasman JW, Dorsey MJ. Complete DiGeorge syndrome associated with CHD7 mutation. J Allergy Clin Immunol. 2007;120(4):952-4. https://doi.org/10.1016/j.jaci.2007.08.013.

59. Writzl K, Cale CM, Pierce CM, Wilson LC, Hennekam RC. Immunological abnormalities in CHARGE syndrome. Eur J Med Genet. 2007;50(5):338-45. https://doi.org/10.1016/j. ejmg.2007.05.002.

60 Jyonouchi S, McDonald-McGinn DM, Bale S, Zackai EH, Sullivan KE. CHARGE (coloboma, heart defect, atresia choanae, retarded growth and development, genital hypoplasia, ear anomalies/deafness) syndrome and chromosome 22 q11.2 deletion syndrome: a comparison of immunologic and nonimmunologic phenotypic features. Pediatrics. 2009;123(5):e871-7. https://doi.org/10.1542/peds. 2008-3400.

61. Liu N, Schoch K, Luo X, Pena LDM, Bhavana VH, Kukolich $\mathrm{MK}$, et al. Functional variants in TBX2 are associated with a syndromic cardiovascular and skeletal developmental disorder. Hum Mol Genet. 2018;27(14):2454-65. https://doi.org/ 10.1093/hmg/ddy 146.

62. Bernstock JD, Totten AH, Elkahloun AG, Johnson KR, Hurst $\mathrm{AC}$, Goldman $\mathrm{F}$ et al. Recurrent microdeletions at chromosome 2 p11.2 are associated with thymic hypoplasia and features resembling DiGeorge syndrome. J Allergy Clin Immunol. 2020;145(1):358-67 e2. doi:https://doi.org/10.1016/j.jaci.2019. 09.020 .

63. Dornemann R, Koch R, Mollmann U, Falkenberg MK, Mollers $\mathrm{M}, \mathrm{Klockenbusch} \mathrm{W}$, et al. Fetal thymus size in pregnant women with diabetic diseases. J Perinat Med. 2017;45(5):595-601. https://doi.org/10.1515/jpm-2016-0400.

64. Wang R, Martinez-Frias ML, Graham JM Jr. Infants of diabetic mothers are at increased risk for the oculo-auriculo-vertebral sequence: a case-based and case-control approach. J Pediatr. 2002;141(5):611-7. https://doi.org/10.1067/mpd.2002.128891.

65. Coberly S, Lammer E, Alashari M. Retinoic acid embryopathy: case report and review of literature. Pediatr Pathol Lab Med. 1996;16(5):823-36.

66. Brown H, Mason G, Tang T. Retinoids and pregnancy: an update. Obstet Gynaecol. 2014;16:7-11.

67. Roberts C, Ivins SM, James CT, Scambler PJ. Retinoic acid down-regulates Tbx1 expression in vivo and in vitro. Dev Dyn. 2005;232(4):928-38. https://doi.org/10.1002/dvdy.20268. 
68. Mulder GB, Manley N, Maggio-Price L. Retinoic acidinduced thymic abnormalities in the mouse are associated with altered pharyngeal morphology, thymocyte maturation defects, and altered expression of Hoxa3 and Pax1. Teratology. 1998;58(6):263-75. https://doi.org/10.1002/(SICI)10969926(199812)58:6\%3c263::AID-TERA8\%3e3.0.CO;2-A.

69. Devriendt K, Fryns JP, Mortier G, van Thienen MN, Keymolen $\mathrm{K}$. The annual incidence of DiGeorge/velocardiofacial syndrome. J Med Genet. 1998;35(9):789-90. https://doi.org/10.1136/jmg. 35.9.789-a.

70 Tezenas Du Montcel S, Mendizabai H, Ayme S, Levy A, Philip N. Prevalence of 22q11 microdeletion. J Med Genet. 1996;33(8):719. https://doi.org/10.1136/jmg.33.8.719.

71. Issekutz KA, Graham JM Jr, Prasad C, Smith IM, Blake KD. An epidemiological analysis of CHARGE syndrome: preliminary results from a Canadian study. Am J Med Genet A. 2005;133A(3):309-17. https://doi.org/10.1002/ajmg.a.30560.

72. Wilson DI, Cross IE, Burn J. Minimum prevalence of chromosome 22q11 deletions. In: Annual Meeting of the American Society of Human Genetics. Am J Hum Genet. 1994 Oct; Montreal, Canada;55(suppl 3).

73 Rope AF, Cragun DL, Saal HM, Hopkin RJ. DiGeorge anomaly in the absence of chromosome 22q11.2 deletion. J Pediatr. 2009;155(4):560-5. https://doi.org/10.1016/j.jpeds.2009.04.010.

74. Amatuni GS, Currier RJ, Church JA, Bishop T, Grimbacher E, Nguyen AA et al. Newborn screening for severe combined immunodeficiency and T-cell lymphopenia in California, 2010-2017. Pediatrics. 2019;143(2). https://doi.org/10.1542/peds.2018-2300.

75. Kong FK, Chen CL, Six A, Hockett RD, Cooper MD. T cell receptor gene deletion circles identify recent thymic emigrants in the peripheral T cell pool. Proc Natl Acad Sci U S A. 1999;96(4):1536-40. https://doi.org/10.1073/pnas.96.4.1536.

76. Yu GP, Nadeau KC, Berk DR, de Saint BG, Lambert N, Knapnougel $\mathrm{P}$, et al. Genotype, phenotype, and outcomes of nine patients with T-B+NK+ SCID. Pediatr Transplant. 2011;15(7):733-41. https://doi.org/10.1111/j.1399-3046.2011. 01563.x.

77. Seet CS, He C, Bethune MT, Li S, Chick B, Gschweng EH, et al. Generation of mature $\mathrm{T}$ cells from human hematopoietic stem and progenitor cells in artificial thymic organoids. Nat Methods. 2017;14(5):521-30. https://doi.org/10.1038/nmeth.4237.

78. Bifsha P, Leiding JW, Pai SY, Colamartino ABL, Hartog N, Church JA, et al. Diagnostic assay to assist clinical decisions for unclassified severe combined immune deficiency. Blood Adv. 2020;4(12):2606-10. https://doi.org/10.1182/bloodadvances. 2020001736.

79. Bosticardo M, Pala F, Calzoni E, Delmonte OM, Dobbs K, Gardner CL, et al. Artificial thymic organoids represent a reliable tool to study T-cell differentiation in patients with severe T-cell lymphopenia. Blood Adv. 2020;4(12):2611-6. https://doi.org/10. 1182/bloodadvances.2020001730.

80. Smith CS, Schoder H, Yeung HW. Thymic extension in the superior mediastinum in patients with thymic hyperplasia: potential cause of false-positive findings on 18F-FDG PET/CT. AJR Am J Roentgenol. 2007;188(6):1716-21. https://doi.org/10.2214/AJR. 06.0552 .

81. Markert ML, Sarzotti M, Ozaki DA, Sempowski GD, Rhein ME, Hale LP, et al. Thymus transplantation in complete DiGeorge syndrome: immunologic and safety evaluations in 12 patients. Blood. 2003;102(3):1121-30. https://doi.org/10.1182/ blood-2002-08-2545.

82. Markert ML, Alexieff MJ, Li J, Sarzotti M, Ozaki DA, Devlin BH, et al. Postnatal thymus transplantation with immunosuppression as treatment for DiGeorge syndrome. Blood. 2004;104(8):257481. https://doi.org/10.1182/blood-2003-08-2984.
83. Selim MA, Markert ML, Burchette JL, Herman CM, Turner JW. The cutaneous manifestations of atypical complete DiGeorge syndrome: a histopathologic and immunohistochemical study. J Cutan Pathol. 2008;35(4):380-5. https://doi.org/10.1111/j.16000560.2007.00816.x.

84. Albuquerque AS, Marques JG, Silva SL, Ligeiro D, Devlin BH, Dutrieux J, et al. Human FOXN1-deficiency is associated with alphabeta double-negative and FoxP3 + T-cell expansions that are distinctly modulated upon thymic transplantation. PLoS ONE. 2012;7(5):e37042. https://doi.org/10.1371/journal.pone.00370 42.

85. Collard HR, Boeck A, Mc Laughlin TM, Watson TJ, Schiff SE, Hale LP, et al. Possible extrathymic development of nonfunctional $\mathrm{T}$ cells in a patient with complete DiGeorge syndrome. Clin Immunol. 1999;91(2):156-62. https://doi.org/10.1006/clim. 1999.4691.

86. Vu QV, Wada T, Toma T, Tajima H, Maeda M, Tanaka R, et al. Clinical and immunophenotypic features of atypical complete DiGeorge syndrome. Pediatr Int. 2013;55(1):2-6. https://doi.org/ 10.1111/j.1442-200X.2012.03722.x.

87. Junker AK, Chan KW, Massing BG. Clinical and immune recovery from Omenn syndrome after bone marrow transplantation. J Pediatr. 1989;114(4 Pt 1):596-600. https://doi.org/10.1016/ s0022-3476(89)80702-4.

88. Ocejo-Vinyals JG, Lozano MJ, Sanchez-Velasco P, Escribano de Diego J, Paz-Miguel JE, Leyva-Cobian F. An unusual concurrence of graft versus host disease caused by engraftment of maternal lymphocytes with DiGeorge anomaly. Arch Dis Child. 2000;83(2):165-9. https://doi.org/10.1136/adc.83.2.165.

89. Davies EG, Cheung M, Gilmour K, Maimaris J, Curry J, Furmanski A et al. Thymus transplantation for complete DiGeorge syndrome: European experience. J Allergy Clin Immunol. 2017;140(6):1660-70 e16. https://doi.org/10.1016/j.jaci.2017. 03.020 .

90. Rice HE, Skinner MA, Mahaffey SM, Oldham KT, Ing RJ, Hale LP, et al. Thymic transplantation for complete DiGeorge syndrome: medical and surgical considerations. J Pediatr Surg. 2004;39(11):1607-15. https://doi.org/10.1016/j.jpedsurg.2004. 07.020 .

91. Janda A, Sedlacek P, Mejstrikova E, Zdrahalova K, Hrusak O, Kalina T, et al. Unrelated partially matched lymphocyte infusions in a patient with complete DiGeorge/CHARGE syndrome. Pediatr Transplant. 2007;11(4):441-7. https://doi.org/10.1111/j. 1399-3046.2007.00702.x

92. Gaspar HB, Qasim W, Davies EG, Rao K, Amrolia PJ, Veys P. How I treat severe combined immunodeficiency. Blood. 2013;122(23):3749-58. https://doi.org/10.1182/ blood-2013-02-380105.

93. Griffith LM, Cowan MJ, Notarangelo LD, Puck JM, Buckley RH, Candotti $\mathrm{F}$ et al. Improving cellular therapy for primary immune deficiency diseases: recognition, diagnosis, and management. $\mathbf{J}$ Allergy Clin Immunol. 2009;124(6):1152-60 e12. https://doi. org/10.1016/j.jaci.2009.10.022.

94. Dergousoff BA, Vayalumkal JV, Wright NAM. Survey of Infection control precautions for patients with severe combined immune deficiency. J Clin Immunol. 2019;39(8):753-61. https:// doi.org/10.1007/s10875-019-00671-y.

95 McDonald-McGinn DM, Sullivan KE, Marino B, Philip N, Swillen A, Vorstman JA, et al. 22q11.2 deletion syndrome. Nat Rev Dis Primers. 2015;1:15071. https://doi.org/10.1038/nrdp.2015. 71.

96. Rivers L, Gaspar HB. Severe combined immunodeficiency: recent developments and guidance on clinical management. Arch Dis Child. 2015;100(7):667-72. https://doi.org/10.1136/ archdischild-2014-306425. 
97. Reid B, Courtney S. Isolation protocol for patients with severe combined immune deficiency. LymphoSign Journal. 2015;2(3). https://doi.org/10.14785/lpsn-2015-0011.

98. Medical Advisory Committee of the Immune Deficiency F, Shearer WT, Fleisher TA, Buckley RH, Ballas Z, Ballow M, et al. Recommendations for live viral and bacterial vaccines in immunodeficient patients and their close contacts. J Allergy Clin Immunol. 2014;133(4):961-6. https://doi.org/10.1016/j.jaci. 2013.11.043.

99. Hofstetter AM, Jakob K, Klein NP, Dekker CL, Edwards KM, Halsey NA, et al. Live vaccine use and safety in DiGeorge syndrome. Pediatrics. 2014;133(4):e946-54. https://doi.org/10.1542/ peds.2013-0831.

100 Perez EE, Bokszczanin A, McDonald-McGinn D, Zackai EH, Sullivan KE. Safety of live viral vaccines in patients with chromosome 22q11.2 deletion syndrome (DiGeorge syndrome/velocardiofacial syndrome). Pediatrics. 2003;112(4):e325. https://doi. org/10.1542/peds.112.4.e325.

101. Gennery AR, Slatter MA, Grandin L, Taupin P, Cant AJ, Veys $\mathrm{P}$ et al. Transplantation of hematopoietic stem cells and longterm survival for primary immunodeficiencies in Europe: entering a new century, do we do better? J Allergy Clin Immunol.
2010;126(3):602-10 e1-11. https://doi.org/10.1016/j.jaci.2010. 06.015 .

102. Haddad E, Hoenig M. Hematopoietic stem cell transplantation for severe combined immunodeficiency (SCID). Front Pediatr. 2019;7:481. https://doi.org/10.3389/fped.2019.00481.

103. Markert ML, Li J, Devlin BH, Hoehner JC, Rice HE, Skinner MA, et al. Use of allograft biopsies to assess thymopoiesis after thymus transplantation. J Immunol. 2008;180(9):6354-64. https://doi.org/10.4049/jimmunol.180.9.6354.

104. Markert M, Gupton S, McCarthy E. Results of 105 patients who received cultured thymus tissue implants. In: 12th Annual Meeting of the Clinical Immunology Society: 2021 Virtual Annual Meeting: Immune Deficiency and Dysregulation North American Conference. J Clin Immunol. 2021 Apr; Virtual;41(Suppl 1).

105. Hasten E, Morrow BE. Tbx 1 and Foxi3 genetically interact in the pharyngeal pouch endoderm in a mouse model for $22 \mathrm{q} 11.2$ deletion syndrome. PLoS Genet. 2019;15(8):e1008301. https:// doi.org/10.1371/journal.pgen.1008301.

Publisher's Note Springer Nature remains neutral with regard to jurisdictional claims in published maps and institutional affiliations. 